\title{
Study on College English Cultural Environment and Hidden Curriculum Development
}

\author{
Xin Wang \\ Liaoning Jidian Polytechnic, Dandong, 118009, China
}

Keywords: College English, Hidden curriculum, English cultural environment, Development, mode

\begin{abstract}
Hidden curriculum is relative to explicit curriculum. In Chinese higher education, universities and teachers pay more attention to explicit conventional and official curriculums as well as some well-organized extracurricular activities, but neglect teaching of hidden curriculums. This is very one-sided educational concept. Thus, based on the background of English teaching, this paper hopes to regard digging actual English cultural environment as the orientation and explore how Chinese universities study and design hidden curriculums under existing cultural environment so as to improve college English teaching environment.
\end{abstract}

\section{Introduction}

In recent years, all-round and deep reform had been conducted for Chinese college education. Teaching quality boosts obviously, and students' quality also improve greatly. Although in the previous reform process, college English education does not pay attention to hidden curriculum, but is high on explicit curriculum reform. Favorable cultural environment in campus and off-campus social environment also drive students' enthusiasm for learning English. If hidden curriculum teaching can be further valued and designed in college English education system, students' English level may further improve.

\section{Connotation of hidden curriculum}

Hidden curriculum belongs to typical curriculum inferior concept. Everyone understands it differently, so hidden curriculum actually has no very exact definition. In 1968, American sociologist Jackson proposed the concept of "hidden classroom" in Life in Classroom the first time. In his opinion, school education can reflect students' view on society, i.e. social value, such as "cooperation”, “tolerance”, “patience” and "discipline abidance”. Students do not learn the ideology and value ideas from classroom, but gradually accumulate them during communication with people. So, Jackson proposed a famous inference “all will clearly find students' progress in learning process does not represent complete result of school education after thinking. Besides, students also acquire life experience in school life, attitude to life, motivation of behavior and behavior value and some psychological states influencing human growth. These unconventional education results are more influential than conventional education results in classroom.” Once this inference is put forward, hidden curriculum which describes informal and unconventional school culture learning process owns stable scientific foundation for study and trial ${ }^{[1]}$.

\section{Development of college English cultural environment}

As stated above, the influence of hidden curriculum comes from campus life, so it is very important for college campus to own favorable learning environment atmosphere. Aiming at English teaching, China pointed out in College English Teaching Requirements at the beginning of 2000, college English teaching should not just boost students' English ability, but also pay more attention to cultivating students' English culture quality and cross-cultural communication competence. Essentially, these changes in policy and environment regard implementation of college English 
hidden curriculum as the goal. In conclusion, the primary task of college English to carry out hidden curriculum is to develop campus English cultural environment.

\section{Improve contents of English reading materials}

There are many English reading materials in college campus. They come from classroom, library and network. So, colleges should make efforts in the three aspects in terms of educational management, i.e. improve the quality of English reading and writing teaching materials, reading periodicals, listening textbooks and extracurricular reading materials. It is required to focus on college English textbooks, recommend some English periodicals and novels suitable to students, help them expand English competence and even communicate with others in English. For example, when a university adopted New Horizon College English, the teacher specially prepared English periodicals about human life value orientation for students in the first lesson "How to make a good impression" , and asked students to write review after reading recommended periodicals to create the chance to communicate with students through discussing the review. Such communication cannot be seen in traditional college English teaching. With such method, some students of science and engineering who seldom contact and dabble in English literature and culture also have the chance to dig their potential interests, draw close to others through learning English and generate effective communication. This is the process of improving and digging hidden curriculum through English textbooks and reading materials. In this process, English teacher as a guide appears and helps students make up for humanistic quality and cultural deposits they cannot learn in traditional English culture curriculum. Although such hidden curriculum is subtle, and maybe students do not realize they learn English culture in communication, they will gradually see learning interestingness of English explicit interestingness. Thus, even if based on fixed teaching mode such as teaching materials and reading materials, students may well contact English hidden curriculum and be immersed in favorable college English cultural environment.

\section{Improve students' autonomous learning initiative and language awareness}

At present, since college English teaching materials are inflexible, students; learning initiative cannot be aroused. Many students are indolent and slack in learning and skip classes frequently. They have no awareness for English learning at all. This is not just a loss for students, but also consumes teachers' teaching attitude. So, it is required to try all means to boost students' learning initiative and let them own English learning awareness.

Firstly, carry out more activities based on English teaching, such as lecture contest, cultural party with foreign students, even traveling abroad for study and improving learning interest and desire of college students.

Secondly, emphasize classroom teaching freedom, and design student-based teaching link, i.e. "people-oriented" teaching method. Favorable classroom deign is also a kind of cultural delivery. In this way, students' sense of achievement and self-confidence can be enhanced in English study.

Thirdly, establish clubs based on English study, such as film and television club and film and television dubbing club. Students can learn English and participate in English communication through watching films and listening to music. It is a good method which can subjectively motivate students to learn English with the help of hobbles of contemporary college students.

Finally, good at utilizing internet resources to guide students to look up and collect knowledge and materials about English study for standby application after class. Nowadays, some English tests set up in colleges exist based on explicit curriculum. Hidden curriculum can be established and reflected by taking explicit curriculum as the core. Internet contains all, including massive English-related knowledge. Regardless of in class and after class, teachers should be good at applying internet and multimedia to help students boost English learning desire and ability ${ }^{[2]}$. 


\section{Study on college English hidden curriculum based on curriculum design}

\section{Mode design of English hidden curriculum}

After college English cultural environment is expanded and developed from three aspects (school management, teacher' s teaching and students' ability training), development and design of English hidden curriculum will be implemented. Hidden foreign curriculum design is a kind of integration and management of English cultural environment and learning resource. Therefore, it is required to impart language teaching concept on the basis of curriculum design. It is a rational and necessary process. English curriculum has particularity different from other disciplines. Firstly, it is a discipline with education nature, so English-based teaching and curriculum design contain certain guidance significance. Secondly, it is an independent discipline. The theory it depends on is different from other disciplines and even other language disciplines, so colleges should establish different teaching modes to expand the teaching range of English hidden curriculum and make it give play to greater education function.

\section{Objective-based hidden curriculum design}

Objective-based hidden curriculum design is the most classical mode. Objective mode will first design four basic questions for English hidden curriculum. Question 1, which education goals should colleges pursue in English teaching? Question 2, which education experience should be provided for students to help them achieve the goal of booting English and learning ability? Question 3, how to effectively organize and utilize mature education experience? Question 4, how to confirm the set objective is in the realization process? English hidden curriculum design may be expanded by focusing on the four questions. The basic links should mainly include objective establishment, experience selection, content organization and result evaluation. For example, in English hidden curriculum based on objective which is organized by a college, teachers first choose English periodicals suitable for students and then create group learning environment for students. Group learning generally lasts for three weeks. After three weeks, debate competition or lecture contest based on knowledge and topic in English reading materials may be organized in English class to examine students' English reading situations. Besides, students and teachers can share reading experience, exchange English learning contents and reach group learning purpose through collective competition mode. This is English hidden learning process based on objective mode. It utilizes the function and technology which derive from objective design to help students actively understand English study and improve learning methods. More importantly, it can stimulate students' subjective initiative.

\section{Hidden curriculum design based on situational mode}

Situational mode sets every education unit to a flexible educational environment. In educational environment, although its characteristic is independent, it also has correlation with other education units. English hidden curriculum based on situational mode should be designed according to different educational environments and conditions. Generally speaking, it mainly includes 5 constituent parts.

Analyze the situation

For college English hidden teaching, analyzing the situation is to analyze English cultural environment, school management, teachers' teaching level and students' learning cognition ability. Combining these factors can formulate objectives for implementing English hidden curriculum.

\section{Define objectives}

Educator Skilbeck considers the most important step is to analyze objectives except specifying situation in hidden curriculum design. Isolated curriculum design can be activated from the objective. For example, teachers design English competition in order to improve students' English, conduct academic exchange with other students and appreciate English culture, instead of winning the competition. Therefore, implementation of English education activity should be based on students' favor, value orientation and judgment of teaching feasibility. If these factors are valuable, the set objective is also valuable. 
Design the teaching learning program

Teaching learning program design mainly includes teachers' design of teaching activity scheme, selection of teaching materials and tools and creation of teaching environment. Cultural atmosphere of English study will not exist without foundation. It is necessary to deliberately create atmosphere and render atmosphere. Some skilful conceptions designed for English classroom can motivate students' learning desire. Such preparatory work tests teachers' teaching organization ability.

Interpret and implement the program

The teaching program designed by teachers should be expounded to students in advance. For example, a teacher designs a game to drive students' learning. He should first set forth the game rules, and then students can take active part in it. The implementation of hidden curriculum program may encounter all kinds of problems, such as insufficient participation degree, teachers; insufficient experience or uncompleted teaching activity. Thus, hidden curriculum implementation is a hidden curriculum systems project. What it creates is not students' English performance or English teaching measure, but cultivation of English cultural environment. If curriculum program implementation encounters difficulties, they should be solved through experience and researches. Experienced teachers should be able to predict and confirm possible difficulties in implementing hidden teaching under situational mode, so communication among students should be enhanced, ad the purpose of hidden curriculum implementation under situational mode should be specified.

Assess and evaluate

Assessment and evaluation refer to the question mentioned above, "how to prove the set hidden curriculum objective is being implemented?” Assessment and evaluation are more objective and conventional in analysis of classroom activity. Teachers should record such data as curriculum design, student engagement and student participation achievements while implementing hidden curriculum so as to help complete after-class evaluation.

On the whole, the first focus of English hidden curriculum education based on situational mode should be the school. The establishment of campus English cultural environment can be furthest exerted and promoted, and students' English learning interest in hidden curriculum through regarding hidden curriculum as standard curriculum of the school. It can be said that situational design is closer to the linkage between social factors and cultural factors. It really defines college campus as a small society, while English hidden curriculum is exactly the bond connecting students' cultural life ${ }^{[3]}$.

\section{Summary}

Development of college English cultural environment and English hidden curriculum is a very an abstract thing for education. It needs joint efforts of school, teachers and students in order to form a set of complete and executable teaching thinking system with return value. So, for the research in this paper, it describes a concept and imagination, rather than actual design of a lesson or an activity. Because the author considers hidden curriculum should be an endless and complex system project for colleges and talent development. It imposes more influence on explicit curriculum. College campus is the place to study academics and share culture. Hidden curriculum exactly needs such atmosphere. Hence, from the perspective of perceptual cognizance, it is very necessary for colleges to develop hidden curriculum and create cultural environment.

\section{Acknowledgments}

This paper is the achievement of 2015 college teaching and research project of Liaoning Jidian Polytechnic, which name is study on campus English culture construction characterized by 'hidden curriculum development', project No.: JYLX15045 


\section{References}

[1] Wang Zhengsheng, Huang Xiumin, Review of two-year study on domestic college English hidden curriculum. English Teacher, 2012, 12(5): 54-58.

[2] Wang He, Construction of material cultural environment of college English and hidden curriculum. Modern Communication, 2014, (6): 234-235.

[3] Shi Guangxiao, Study on college English curriculum design from perspective of hidden curriculum. Shanghai International Studies University, 2011. 90-94. 